\title{
Povidone-iodine induced post-surgical irritant contact dermatitis localized outside of the surgical incision area. Report of 27 cases and a literature review
}

\author{
Leopoldo Borrego, MD, Noelia Hernández, MD, Zaida Hernández, MD, and \\ Yeray Peñate, MD
}

\author{
Servicio de Dermatología, Hospital \\ Universitario Insular, Universidad de Las \\ Palmas de Gran Canaria, Las Palmas de \\ Gran Canaria, Spain \\ Correspondence \\ Leopoldo Borrego, MD \\ Servicio de Dermatología, \\ Hospital Universitario Insular \\ Universidad de Las Palmas de Gran \\ Canaria \\ Avda Marítima s/n, 35016 \\ Las Palmas de Gran Canaria \\ Spain \\ E-mails: Iborher@gobiernodecanarias.org; \\ lborrego@dcmq.ulpgc.es
}

Conflicts of interest: None.

\begin{abstract}
Background Povidone-iodine solution is an antiseptic that is used worldwide as surgical paint and is considered to have a low irritant potential. Post-surgical severe irritant dermatitis has been described after the misuse of this antiseptic in the surgical setting. Methods Between January 2011 and June 2013, 27 consecutive patients with postsurgical contact dermatitis localized outside of the surgical incision area were evaluated. Thirteen patients were also available for patch testing.

Results All patients developed dermatitis the day after the surgical procedure. Povidoneiodine solution was the only liquid in contact with the skin of our patients. Most typical lesions were distributed in a double lumbar parallel pattern, but they were also found in a random pattern or in areas where a protective pad or an occlusive medical device was glued to the skin. The patch test results with povidone-iodine were negative.

Conclusions Povidone-iodine-induced post-surgical dermatitis may be a severe complication after prolonged surgical procedures. As stated in the literature and based on the observation that povidone-iodine-induced contact irritant dermatitis occurred in areas of pooling or occlusion, we speculate that povidone-iodine together with occlusion were the causes of the dermatitis epidemic that occurred in our surgical setting. Povidone-iodine dermatitis is a problem that is easily preventable through the implementation of minimal routine changes to adequately dry the solution in contact with the skin.
\end{abstract}

\section{Introduction}

Irritant contact dermatitis is one of the most prevalent skin diseases in hospitalized patients. ${ }^{\mathrm{I}}$ Povidone-iodine (PVP-I) solution is used worldwide as surgical paint because of its potent germicidal activity. ${ }^{2}$ Povidone is an effective iodophor that complexes with iodine in aqueous solution. A I०\% PVP-I solution contains I0\% bound iodine and I\% available iodine, making it less toxic and irritating than pure iodine solutions. Although it is considered to have a low irritant potential, scattered cases of severe skin injury have been associated with the use of PVP-I in the surgical setting. ${ }^{3-33}$ In this series, our patients developed contact dermatitis, which was localized in areas of embedded medical devices that were painted with PVP-I as well as in areas where PVP-I was suspected to have pooled during the surgical

\section{Materials and methods}

Between January 2011 and June 2013, 27 patients were referred to the Contact Dermatitis Unit of the Hospital Universitario Insular due to acute dermatitis that developed after surgical procedures (Table 1). Twenty-four patients were evaluated as inpatients of our hospital and were referred to the dermatologic outpatient clinic, and the other three patients underwent surgery at another hospital. Of the 24 inpatients, one underwent surgery in the maternal surgical department (patient 5 ), and the remainder of patients underwent an operation in the general surgical department. Thirteen patients were available for patch testing. All patients were patch tested using the Spanish baseline series, plastics and glue series (Chemotechnique Diagnostics, Vellinge, Sweden), and DrugsAntiseptics series (Marti Tor, Barcelona, Spain), which includes $10 \%$ PVP-I aqueous solution and $0.5 \%$ iodine pet. Readings of the tests were performed on D2 and D4. 
Table 1 Clinical data

\begin{tabular}{|c|c|c|c|c|c|}
\hline Patient & Age/sex & Clinical condition & $\begin{array}{l}\text { Duration } \\
\text { of procedure } \\
\text { (h) }\end{array}$ & Area/clinical pattern & Patch test results \\
\hline 1 & $59 / \mathrm{M}$ & $\begin{array}{l}\text { Cholectomy } \\
\text { Intestinal polyposis }\end{array}$ & 3 & $\begin{array}{l}\text { Parallel lumbar pattern, } \\
\text { electrosurgery returning } \\
\text { terminal, } 1 \text { electrocardiogram } \\
\text { terminal }\end{array}$ & Neg. \\
\hline 2 & $36 / F$ & Bowel reduction & 4 & $\begin{array}{l}\text { Parallel lumbar pattern, } \\
\text { electrocardiogram terminals }\end{array}$ & Nickel, 4-tert-butylcatechol \\
\hline 3 & $31 / \mathrm{M}$ & $\begin{array}{l}\text { Laparoscopic cholecystectomy. } \\
\text { Son of patient } 6\end{array}$ & 1 & Left buttock & Neg. \\
\hline 4 & $37 / F$ & Left ankle compound fracture & 5 & $\begin{array}{l}\text { Back, back of the arms, } \\
\text { left thigh; blisters }\end{array}$ & Neg. \\
\hline 5 & $33 / F$ & Endometriosis. Laparoscopy & $1 \frac{1}{2}$ & Buttocks & $\begin{array}{l}\text { Thimerosal, } \\
\text { ethylenediamine } \\
\text { dihydrochloride }\end{array}$ \\
\hline 6 & $57 / F$ & Mastectomy. Breast cancer & 4 & $\begin{array}{l}\text { Left shoulder, lumbar left, } \\
\text { buttocks }\end{array}$ & $\begin{array}{l}\text { Nickel, PVP-I 10\% aq } \\
\text { ROAT: Negative }\end{array}$ \\
\hline 7 & $62 / \mathrm{M}$ & Sigmoidectomy, colon carcinoma & $2 \frac{1}{2}$ & Parallel lumbar pattern & Nickel \\
\hline 8 & $63 / F$ & Knee prosthesis & $4 \frac{1}{2}$ & $\begin{array}{l}\text { Back, back of the arms, } \\
\text { left thigh; blisters }\end{array}$ & Neg. \\
\hline 9 & $63 / \mathrm{F}$ & $\begin{array}{l}\text { Bowel reconstruction, previous } \\
\text { colon carcinoma }\end{array}$ & 3 & Parallel lumbar pattern; buttocks & Nickel \\
\hline 10 & $52 / \mathrm{M}$ & Sigmoidectomy, colon carcinoma & 2 & Parallel lumbar pattern & Nickel \\
\hline 11 & $53 / \mathrm{M}$ & Right inguinal deep lipoma & $11 / 2$ & Left thigh and buttock & $\begin{array}{l}\text { Methyldibromo } \\
\text { glutaronitrile } \\
\text { Tixocortol pivalate }\end{array}$ \\
\hline 12 & $53 / \mathrm{M}$ & $\begin{array}{l}\text { Bowel reconstruction, previous } \\
\text { colon carcinoma }\end{array}$ & 3 & Parallel lumbar pattern; buttocks & $\begin{array}{l}\text { Methyldibromo } \\
\text { glutaronitrile }\end{array}$ \\
\hline 13 & $67 / \mathrm{M}$ & $\begin{array}{l}\text { Colectomy, splenectomy } \\
\text { colon carcinoma }\end{array}$ & 4 & Upper back, buttocks & Neg. \\
\hline 14 & $43 / \mathrm{M}$ & Right knee prosthesis & $4 \frac{1}{2}$ & $\begin{array}{l}\text { Left calf, border of pneumatic } \\
\text { tourniquet on right thigh }\end{array}$ & NP \\
\hline 15 & $60 / \mathrm{M}$ & Segmentectomy, lung carcinoma & 3 & Linear, bullous lesions on the back & NP \\
\hline 16 & $63 / \mathrm{M}$ & $\begin{array}{l}\text { Squamous cell carcinoma } \\
\text { of the mouth }\end{array}$ & 5 & Both shoulders & NP \\
\hline 17 & $50 / \mathrm{M}$ & Diverticulitis, bowel reconstruction & 2 & $\begin{array}{l}\text { Right axilla, buttocks, right thigh; } \\
1 \text { electrocardiogram electrode, } \\
\text { left part of the thorax }\end{array}$ & NP \\
\hline 18 & $72 / \mathrm{M}$ & Femur fracture & 6 & $\begin{array}{l}\text { Buttocks, right thigh and leg; } \\
\text { medical support devices } \\
\text { of the surgical table }\end{array}$ & NP \\
\hline 19 & $51 / \mathrm{M}$ & $\begin{array}{l}\text { Anal sphincterotomy and } \\
\text { reconstruction }\end{array}$ & $11 / 2$ & Buttocks & NP \\
\hline 20 & $48 / \mathrm{M}$ & Lower back arthrodesis & 3 & Thorax, abdomen & NP \\
\hline 21 & $53 / \mathrm{M}$ & Intestinal resection, colon carcinoma & $2 \frac{1}{2}$ & Parallel lumbar pattern, buttocks & NP \\
\hline 22 & $52 / F$ & Mastectomy, breast cancer & 2 & Upper back, buttocks & NP \\
\hline 23 & $64 / \mathrm{M}$ & Bowel reconstruction, colon carcinoma & 4 & Linear right lumbar area & NP \\
\hline 24 & $63 / M$ & Bowel reconstruction, colon carcinoma, & 3 & Parallel lumbar pattern & NP \\
\hline 25 & $42 / \mathrm{M}$ & Triple cervical arthrodesis & 6 & Upper back, buttocks & NP \\
\hline 26 & $73 / F$ & $\begin{array}{l}\text { Bowel reconstruction, traumatic } \\
\text { intrarectal perforation }\end{array}$ & 3 & Parallel lumbar pattern; erosions & NP \\
\hline 27 & $50 / \mathrm{M}$ & $\begin{array}{l}\text { Abdominal eventration and bowel } \\
\text { reconstruction, previous colon } \\
\text { diverticulitis }\end{array}$ & 4 & $\begin{array}{l}\text { Parallel lumbar pattern; } \\
\text { specular image to grooves } \\
\text { of clinical drapes }\end{array}$ & NP \\
\hline
\end{tabular}

F, female; M, male; Neg., negative patch test results; NP, patch test not performed. 


\section{Results}

The clinical findings, patch test results, duration, and type of procedures are shown in Table I. All patients developed a skin eruption within one day post-surgery. With the exception of three patients, who had the mildest eruptions, surgical procedures lasted for more than two hours. All patients presented well-demarcated erythematous plaques. Nine patients had erosions or vesicles. Of these patients, five patients also had bullae, and two patients had residual scaling. None of our patients presented with necrosis. Fourteen patients had lesions with signs of dropping figures (Fig. I). Twenty-two patients presented lesions on the back. Ten of these patients presented lesions on both sides of the shoulders and back in a parallel distribution (Fig. 2). Three patients presented annular-

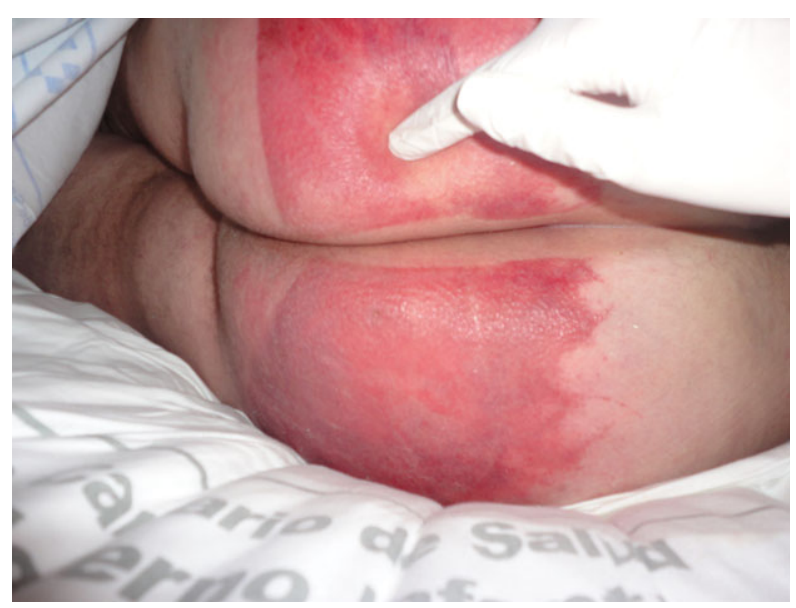

Figure 1 Patient 17. Dropping lesions located in the buttocks

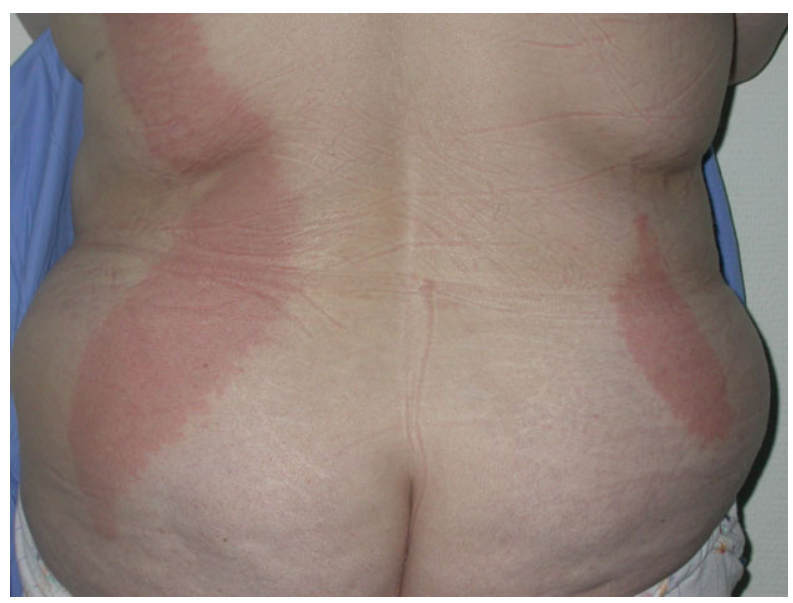

Figure 2 Patient 2. Lesions located in a double lumbar parallel pattern shaped lesions located in the area of the electrocardiogram electrode. One patient presented with lesions below the site where the return electrosurgery plate was placed, and another patient had lesions where the skin came into contact with the arm of the surgical table used by the orthopedic surgery department; one patient also had lesions at the border of the pneumatic tourniquet. One patient had lesions in a rhomboidal pattern matching the grooves of the surgical drape used during the procedure. None of the patients had dermatitis at the incision area. The only liquid that contacted the patient's skin during the surgical procedure was Betadine Sol Dermica ${ }^{\circledR}$ (Meda Pharma SAU; Meda Manufacturing, Bordeaux, France). This antiseptic is a I०\% PVP-I aqueous solution with glycerin, nonoxynol-9, disodium phosphate, citric acid, and sodium hydroxide as excipients. Only patient 6 presented a positive reaction to I0\% aqueous PVP-I, but the repeated open application test (ROAT) with Betadine Sol Dermica (r) and Io\% aqueous PVP-I solution was negative.

\section{Comment}

In this study, we analyzed a series of patients over a 2-year period who presented with post-surgical dermatitis that was localized away from the site of the surgical incision. A meticulous and strict investigative program was performed. Pre-, intra-, and postoperative nursing procedures as well as the habits of surgeons were evaluated. The antiseptics used to clean surgical tables were also considered. Betadine Sol Dermica was considered as the only possible cause of the dermatitis. The fact that surgical incisions and postoperative daily painting with the same solution did not result in complications were confounding factors in making an initial appropriate diagnosis. Only one patient reacted to the I०\% aqueous PVP-I in the patch test, but the ROAT using I०\% aqueous PVP-I and Betadine Sol Dermica ( $r$ ) was negative. Allergic contact dermatitis from PVP-I has been reported over the last 30 years (Table 2), ${ }^{6-16,34,35}$ but, in the case of patients, the lesions were located where the antiseptic had been applied. De la Cuadra-Oyanguren et al. ${ }^{6}$ presented two cases of allergic contact dermatitis in whom the incisional area, also painted with PVP-I, was free of dermatitis. In these cases, the patch test was positive to PVP-I in petrolatum, but the ROAT test was negative. ${ }^{2,3,6}$

Intolerance to antiseptics can also be the result of other components in the preparations. Allergic contact dermatitis to nonoxynol-9 present in the PVP-I solutions has been previously shown, ${ }^{36}$ and this substance is found in Betadine Sol Dermica (r). Unfortunately, we did not have the opportunity to perform a patch test of all of the components of the solution to exclude nonoxynol-9 sensitization. Similar to the cases of allergic contact dermatitis 
Table 2 Literature review

\begin{tabular}{|c|c|c|c|c|c|c|}
\hline Patient & No. of cases & Surgical procedure & Location & $\begin{array}{l}\text { Incisional } \\
\text { site affected }\end{array}$ & Allergic/irritant & Ref. \\
\hline 1 & 27 & Table 1 & & No & Irritant & \\
\hline \multirow[t]{2}{*}{2} & 2 & Uterine prolapse/hand surgery & Gluteal area/tourniquet & No & Allergic and irritant & 6 \\
\hline & 5 & $\begin{array}{l}\text { Melanocytic nevus/bone biopsy/colon } \\
\text { carcinoma/knee prosthesis/ } \\
\text { pneumothorax }\end{array}$ & At the site of procedure & Yes & Allergic and irritant & \\
\hline 3 & 1 & Articular infiltration & Elbow & Yes & Allergic and irritant & 7 \\
\hline 4 & 1 & Hip replacement & Hip & Yes & Allergic & 8 \\
\hline 5 & 1 & Pelvic surgery & Genital area & Yes & Probably allergic & 9 \\
\hline 6 & 1 & Carpal tunnel release & Left hand & Yes & Allergic & 10 \\
\hline 7 & 1 & Right knee prosthesis & Right lower limb & Yes & Allergic & 11 \\
\hline 8 & 1 & & Abdomen & Not available & Allergic & 12 \\
\hline 9 & 2 & Right foot/right kidney surgery & Right foot/right flank & Yes & Allergic & 13 \\
\hline 10 & 1 & Not available & At the site, limbs and trunk & Yes & Allergic erythema multiforme & 14 \\
\hline 11 & 2 & $\begin{array}{l}\text { Achilles tendon repair/peripheral } \\
\text { vascular disease surgery }\end{array}$ & Right ankle, artery access & Yes & Allergic & 15 \\
\hline 12 & 1 & Cholecystectomy & $\begin{array}{l}\text { Back, gluteal area, } \\
\text { inner arm }\end{array}$ & Not available & Allergic & 16 \\
\hline 13 & 1 & Cruciate ligament reconstruction & Left leg & No & Chemical burn & 17 \\
\hline 14 & 2 & Left knee surgery/knee arthroplasty & Tourniquet & No & Chemical burn & 18 \\
\hline 15 & 1 & Acute appendicitis & Buttocks & No & Irritant/burn & 4 \\
\hline 16 & 1 & Polydactyl reparation & Tourniquet & No & Chemical burn & 19 \\
\hline 17 & 1 & Caesarean under spinal anesthesia & Back & Yes \& folds & Irritant/burn & 20 \\
\hline 18 & 2 & $\begin{array}{l}\text { Cruciate ligament repair/Achilles } \\
\text { tendon lengthening }\end{array}$ & Tourniquet & No & Chemical burn & 21 \\
\hline 19 & 5 & Cardiac patients & Not available & Not available & Chemical burn & 22 \\
\hline 20 & 1 & Aortic valve and aortic aneurysm & Axillae and abdominal folds & No & Irritant NET-like & 23 \\
\hline 21 & 1 & Ovarian cystectomy & Midback - buttocks & No & Irritant & 24 \\
\hline 22 & 1 & Sebaceous cyst & Abdomen and low thorax & Yes & Irritant, Vasculitic-like & 25 \\
\hline 23 & 1 & Subtotal thyroidectomy & Midback & No & Chemical burn & 26 \\
\hline 24 & 2 & Not available & Back/abdomen and chest & Not available & Irritant & 27 \\
\hline \multirow[t]{2}{*}{25} & 12 & Surgery & $\begin{array}{l}\text { Back/buttocks/ } \\
\text { Posterior area of thighs }\end{array}$ & Not available & Irritant & 3 \\
\hline & 7 & Cardioangiography & & & & \\
\hline \multirow[t]{3}{*}{26} & 3 & Flexor tendon repair & Tourniquet & No & Irritant/burn & 28 \\
\hline & & Femoropopliteal bypass graft & Back. Spinal anesthesia & No & Irritant/burn & \\
\hline & & Right iliac endarterectomy. & Left gluteal area & No & Irritant/burn & \\
\hline 27 & 2 & Kidney surgery & Opposite flank & No & Irritant & 29 \\
\hline 28 & 1 & Nissen's fundoplication & Back & No & Irritant & 30 \\
\hline 29 & 1 & Fallot tetralogy & Back & No & Irritant & 5 \\
\hline 30 & 3 & Syndactyly & Tourniquet & No & Chemical burn & 31 \\
\hline 31 & 1 & Delivery/spinal anesthesia & Back & No & Chemical burn & 32 \\
\hline 32 & 2 & Cervix carcinoma & Lower back - sacral area & No & Irritant/burn & 33 \\
\hline
\end{tabular}

due to active principles, the reported cases were located where the antiseptic had been applied. ${ }^{36,37}$ The absence of dermatitis at the site of incision and the patch test results support the hypothesis that irritancy is the predominant cause of the dermatitis in our cases.

PVP-I solution consists of iodine in complex with PVP in equilibrium based on the concentration. If free iodine is used, then more iodine is released, and the iodine concentration is maintained for a longer period. ${ }^{3,4}$ As shown by Dykes and Marks, ${ }^{38}$ irritation due to PVP-I is time dependent, and most of the patients in the present study had long procedures. In addition, excipients present in the solution, occlusion with plastic drapes, waterproof dressings, medical devices (electrosurgical returning plate in patient I), contact with PVP-I-soaked cotton pads used to cover the pneumatic hemostat (patient I4), or contact with the arms of the surgical tables (patient I8) may increase the possible irritancy.

Notably, patient 2 reacted to p-tert-butylcatechol, which is suspected to be present in the electrocardiogram electrode. This patient exhibited dermatitis at the locations of all electrodes and had recurrent dermatitis when the electrodes were used again. Two other patients had typical annular dermatitis at the location 
of one electrode but not the others (patients I and I7). One of these patients underwent patch testing for the same electrode as well as the Chemotechnique Diagnostics plastic and glue series. All patch tests were negative, and the patient tolerated the electrodes after surgery.

In different medical specialties, the misuse of PVP-I can lead to severe irritant reactions similar to caustic or electrical burns. In particular, it has been shown that when PVP-I solutions are not adequately dried and pool beneath a part of the body, a chemical burn-like skin reaction may result. ${ }^{5,23,24,29}$ Based on the literature and our own experience, four different clinical patterns can be described as a result of PVP-I misuse. The first and most distinct pattern consists of a double lumbar parallel pattern. ${ }^{3}$ This pattern is the consequence of the folding and maintenance of moist PVP-I during a surgical procedure in which the patient is maintained in the supine position (Fig. 2). A second pattern is due to embedded cotton or gauze pads used to protect some of the medical devices employed during the procedure, as has been described with the use of tourniquets. ${ }^{6,18,19,21,28,3 \mathrm{I}}$ The third clinical pattern is observed when the lesion delineates a terminal or a device glued to the skin of the patient, as reported in dermatitis occurring after spinal anesthesia. ${ }^{28,32}$ The fourth clinical pattern is a random pattern that follows the folds or grooves of clinical drapes.

Because several of our patients had cancer or the diagnosis of the dermatitis was considered a minor complication, we were unable to analyze fully all patients using patch testing and different dilutions of the solution. Surgeons initially considered the dermatitis a minor problem in many cases, and therefore only severe cases were referred to our department. Most of our cases were only seen after insistence by the patients or surgical nurses. Moreover, some of the dermatitis cases were interpreted by hospital personnel as an allergy to hospital clothing or due to an increase in perspiration. The most severe cases can also be misinterpreted as electrical burns. ${ }^{28}$ Therefore, when a PVP-I or iodine reaction is suspected by the referring clinician, the irritant nature of the dermatitis should be clarified to reassure patients and doctors that they do not need to avoid iodine compounds in the future.

PVD-I dermatitis is a problem that is easily preventable through the implementation of minimal routine changes to adequately dry the solution in contact with the skin. ${ }^{3,24}$

\section{Acknowledgments}

We are indebted to Olga Gil, Nurse-in-Chief at the Surgery Area of the Hospital Universitario Insular, who helped us with all investigations before and after the cause of the dermatitis was suspected.

\section{References}

I Peñate Y, Guillermo N, Melwani P, et al. Dermatologists in hospital wards: an 8-year study of dermatology consultations. Dermatology 2009; 219: 225-23I.

2 Lee SK, Zhai H, Maibach HI. Allergic contact dermatitis from iodine preparations: a conundrum. Contact Dermatitis 2005; 52: I 84-I87.

3 Iijima S, Kuramochi M. Investigation of irritant skin reaction by I0\% povidone-iodine solution after surgery. Dermatology 2002; 204(Suppl. I): 103-108.

4 Rees A, Sherrod Q, Young L. Chemical burn from povidone-iodine: case and review. J Drugs Dermatol 2OII; IO: 4I4-4I7.

5 Okano M. Irritant contact dermatitis caused by povidoneiodine. J Am Acad Dermatol I989; 20: 860.

6 de la Cuadra-Oyanguren J, Zaragoza-Ninet V, SierraTalamantes C. Alegre de Miquel V. Postsurgical contact dermatitis due to povidone iodine: a diagnostic dilemma. Actas Dermosifiliogr 2014; 105: 300-304.

7 Borja JM, Galindo PA, Gomez E, et al. Contact dermatitis due to povidone-iodine: allergic or irritant? J Investig Allergol Clin Immunol 2003; I3: I3 I-I32.

8 Zokaie S, White IR, McFadden JD. Allergic contact dermatitis caused by iodophor-impregnated surgical incise drape. Contact Dermatitis 20II; 65: 309.

9 Rahimi S, Lazarou G. Late-onset allergic reaction to povidone-iodine resulting in vulvar edema and urinary retention. Obstet Gynecol 2010; II6(Suppl 2): 562-564.

ıo Velázquez D, Zamberk P, Suárez R, et al. Allergic contact dermatitis to povidone-iodine. Contact Dermatitis 2009; 60: 348-349.

I I Reichert-Pénétrat S, Barbaud A, Pénétrat E, et al. Allergic contact dermatitis from surgical paints. Contact Dermatitis 200I; 45: II6-II7.

I 2 Nishioka K, Seguchi T, Yasuno $\mathrm{H}$, et al. The results of ingredient patch testing in contact dermatitis elicited by povidone-iodine preparations. Contact Dermatitis 2000; 42: 90-94.

I3 Erdmann S, Hertl M, Merk HF. Allergic contact dermatitis from povidone-iodine. Contact Dermatitis I999; 40: 33I-332.

I4 Torinuki W. Generalized erythema-multiforme-like eruption following allergic contact dermatitis. Contact Dermatitis I990; 23: 202-203.

I 5 Marks JG Jr. Allergic contact dermatitis to povidoneiodine. J Am Acad Dermatol I982; 6: 473-475.

I6 Ancona A, Suárez de la Torre R, Macotela E. Allergic contact dermatitis from povidone-iodine. Contact Dermatitis I985; I3: 66-68.

I7 Supradeeptha C, Shandilya SM, Naresh A, et al. Aqueous based Povidone-iodine related chemical burn under the tourniquet (a case report) and literature review. J Orthop 2OI3; IO: I 52-I 54 . 
I 8 Yang JH, Lim H, Yoon JR, et al. Tourniquet associated chemical burn. Indian J Orthop 20I 2; 46: 356-359.

I9 Chiang YC, Lin TS, Yeh MC. Povidone-iodine-related burn under the tourniquet of a child. A case report and literature review. J Plast Reconstr Aesthet Surg 20I I; 64: 4I 2-4 I 5 .

20 Murthy MB, Krishnamurthy B. Severe irritant contact dermatitis induced by povidone iodine solution. Indian J Pharmacol 2009; 4I: I99-200.

2I Hubik DJ, Connors A, Cleland H. Iatrogenic chemical burns associated with tourniquet use and prep solution. ANZ J Surg 2009; 79: 762.

22 Demir E, ODey DM, Pallua N. Accidental burns during surgery. J Burn Care Res 2006; 27: 895-900.

23 Vandergriff TW, Wasko CA, Schwartz MR, et al. Irritant contact dermatitis from exposure to povidone-iodine may resemble toxic epidermal necrolysis. Dermatol Online J 2006; IO: I 2.

24 Lowe DO, Knowles SR, Weber EA, et al. Povidoneiodine-induced burn: case report and review of the literature. Pharmacotherapy 2006; 26: I64I-I645.

25 Rosina P, Zamperetti MR, Saverio Donghia F, et al. Irritant contact dermatitis with a vasculitic-like pattern from PVP-I. Contact Dermatitis 2006; 55: 304-305.

26 Liu FC, Liou JT, Hui YL, et al. Chemical burn caused by povidone-iodine alcohol solution. A case report. Acta Anaesthesiol Sin 2003; 4I: 93-96.

27 Kozuka T. Patch testing to exclude allergic contact dermatitis caused by povidone-iodine. Dermatology 2002; 204(Suppl. I): 96-98.

28 Nahlieli O, Baruchin AM, Levi D, et al. Povidone-iodine related burns. Burns 200I; 27: I $85^{-1} 88$.
29 Corazza M, Bulciolu G, Spisani L, et al. Chemical burns following irritant contact with povidone-iodine. Contact Dermatitis I997; 36: II 5-II6.

30 Nakano S, Uchiyama A, Ueyama H, et al. [Chemical burn caused by povidone-iodine]. Masui I99I; 40: 8 I $2-8$ I 5 .

3 I Dickinson JC, Bailey BN. Chemical burns beneath tourniquets. $\mathrm{Br}$ Med J I988; 297: I 5 I 3 .

32 Duffy BL. Betadine burn. Anaesth Intensive Care I98I; 9: 401 .

33 Llorens AS. Reaction to povidone-iodine surgical scrub associated with radical pelvic operations. Am J Obstet Gynecol I972; I5: 834-835.

34 Lachapelle JM. Allergic contact dermatitis from povidone-iodine: a re-evaluation study. Contact Dermatitis 2005; 52: 9-10.

35 van Ketel WG, van den Berg WH. Sensitization to povidone-iodine. Dermatol Clin I990; 8: I07-I09.

36 Dooms-Goossens A, Deveylder H, de Alam AG, et al. Contact sensitivity to nonoxynols as a cause of intolerance to antiseptic preparations. J Am Acad Dermatol I989; 21: 723-727.

37 Fettig J, Taylor J, Sood A. Post-surgical allergic contact dermatitis to compound tincture of benzoin and association with reactions to fragrances and essential oils. Dermatitis 20I4; 25 : 2II-2I 2.

38 Dykes PJ, Marks R. An evaluation of the irritancy potential of povidone iodine solutions: comparison of subjective and objective assessment techniques. Clin Exp Dermatol I992; 17: 246-249. 